\title{
Eye contact effect: The role of vagal regulation and reactivity, and self-regulation of attention
}

\author{
Alicja Niedźwiecka ${ }^{1}$ (D) \\ Accepted: 24 March 2021 / Published online: 3 April 2021 \\ (C) The Author(s) 2021
}

\begin{abstract}
Eye contact is a crucial aspect of social interactions that may enhance an individual's cognitive performance (i.e. the eye contact effect) or hinder it (i.e. face-to-face interference effect). In this paper, I focus on the influence of eye contact on cognitive performance in tasks engaging executive functions. I present a hypothesis as to why some individuals benefit from eye contact while others do not. I propose that the relations between eye contact and executive functioning are modulated by an individual's autonomic regulation and reactivity and self-regulation of attention. In particular, I propose that individuals with more optimal autonomic regulation and reactivity, and more effective self-regulation of attention benefit from eye contact. Individuals who are less well regulated and over- or under-reactive and who do not employ effective strategies of self-regulation of attention may not benefit from eye contact and may perform better when eye contact is absent. I present some studies that justify the proposed hypothesis and point to a method that could be employed to test them. This approach could help to better understand the complex mechanisms underlying the individual differences in participant's cognitive performance during tasks engaging executive functions.
\end{abstract}

Keywords Eye contact effect · Face-to-face interference effect · Vagal reactivity and regulation · Self-regulation of attention

This paper presents a hypothesis regarding the relations between eye contact, autonomic reactivity and regulation, and self-regulation of attention during tasks engaging executive functions. I postulate that individuals with more optimal autonomic reactivity and regulation, and more effective selfregulation of attention benefit from eye contact. Individuals who are over- or under-reactive and less well regulated in terms of autonomic regulation, and who do not employ effective strategies of self-regulation of attention may not benefit from eye contact and even may perform better when the eye contact is absent.

First, I will present a brief review of the literature regarding the eye contact effect and face-to-face interference. Then, I will outline the polyvagal theory put forth by Porges (2007) as a context of cognition. Next, I will review some studies examining the relations between vagal regulation, attention, and the control of attention. I will also demonstrate how existing studies with participants with autism spectrum disorders (ASD) can inform our understanding of the eye contact

Alicja Niedźwiecka

a.niedzwiecka@psych.uw.edu.pl

1 Faculty of Psychology, University of Warsaw, Stawki 5/7, 01-121 Warsaw, Poland effect and face-to-face interference and their relations with autonomic reactivity and regulation. Next, I will discuss some findings that point to the role of self-regulation of attention in cognitive performance. Finally, I will argue that the polyvagal theory and the cited empirical findings converge to suggest that the eye contact effect may depend on vagal reactivity and regulation, and self-regulation of attention. I will propose some specific hypotheses and outline a method that could be employed to test them.

\section{Eye Contact and Cognitive Performance}

Eye contact is a crucial aspect of social interactions (for a review see Hessels 2020) but its role and effects vary. Eye contact can facilitate children's (Farroni et al. 2004; Hoehl et al. 2014; Reid and Striano 2005; Wu et al. 2014) and adults' (Hietanen et al. 2016) information processing, a phenomenon known as the eye contact effect (Senju and Johnson 2009). Possible mechanisms underlying the eye contact effect include an early preparedness to process gaze, an informative signal value of direct gaze, and certain specific responses elicited by eye contact with another person (see a review in Niedźwiecka 2020). However, an opposite effect has also been demonstrated, that is the face-to-face interference effect 
(Riby et al. 2012). Eye contact can impede cognitive performance because it may increase cognitive load (e.g., Phelps et al. 2006), act as a distractor (Conty et al. 2010), or disrupt cognitive control (Kajimura and Nomura 2016).

There are also some individual differences in responses to eye contact. First, eye contact differentially affects task performance of typically developing children and children with ASD. In an experiment in which memory performance was compared in two conditions: with and without eye contact with an experimenter, typically developing children performed better when eye contact was present, whereas no such effect was observed in children with ASD (Falck-Ytter et al. 2015). Second, a variation in responses to eye contact can also be observed in neurotypical individuals, as some react with approach behaviors, while others tend to react with avoidance behaviors (Helminen et al. 2011). Thus, certain intraindividual factors seem to modulate the impact of eye contact on cognitive processing.

\section{Vagal Regulation as a Context of Cognition}

An individual's automatic responses to eye contact can be assessed by measuring brain activity (Hietanen et al. 2008), muscle activity (Hietanen et al. 2018), changes in skin conductance (Prinsen et al. 2019), and heart activity (Wieser et al. 2009). A useful theoretical framework for research based on the measurement of heart activity is the polyvagal theory (Porges 2007). The theory offers a model that links changes in peripheral indices of autonomic activity (heart activity) during resting states and during cognitive tasks with neurobiological bases of these changes. It explains the couplings between heart activity and cognitive processes. The polyvagal theory affords testable hypotheses regarding the relations between eye gaze, autonomic reactivity, and cognitive performance.

The polyvagal theory focuses on the balance between three main circuits in the autonomic nervous system, with a particular interest in the functioning of the myelinated fibres of the ventral complex of the vagus. While the dorsal complex of the vagus and the sympathetic system are key to reacting to danger, the ventral complex of the vagus is involved in more complex social behaviors, which are only readily observable when individuals do not perceive any source of danger (Porges 2007). The myelinated vagus inhibits the sympathetic system (turns on the "vagal brake"), resulting in a subjective state of calm. Consequently, various behaviors engaged in establishing social relations can be activated (e.g., making eye contact). A withdrawal of the vagal brake results in an increase of arousal, enabling fight or flight responses. Concurrently, it disfavours social engagement. Eye contact is a crucial element of social engagement, therefore it is compatible with the physiological state warranted by the vagal brake and incompatible with the physiological state following a withdrawal of the vagal brake.

As heart activity is partially controlled by the vagus, cardiac measures have been central to research stemming from the polyvagal theory. Heart rate variability (HRV) and, more specifically, respiratory sinus arrhythmia (RSA) have been used as measures of vagal regulation and reactivity, and as measures of cognitive effort and sustained attention (Porges 2007; Suess et al. 1994). HRV has been conceptualized as an indicator of an overall level of self-regulatory abilities of an individual, as well as an indicator of the effort required to selfregulate during a task (Segerstrom and Nes 2007).

Measures of HRV are used to evaluate the levels of prefrontal cortical control over phylogenetically older structures (Thayer et al. 2009). A more effective regulation results in a higher adaptability and better cognitive performance, especially in tasks recruiting executive functions (Hansen et al. 2004), that is the high-order, effortful cognitive processes, including inhibition, working memory, and cognitive flexibility (Diamond 2013).

Measures of vagal regulation have also been used to assess temperamental reactivity and behavioral self-regulation (Calkins 1997). For instance, a moderate decrease in HRV during tasks has an activating effect, favouring optimal performance. Similarly, a greater vagal withdrawal while viewing a stimulus evoking negative emotions is related to more effective emotion regulation and lower depressive symptoms (Gentzler et al. 2009). Thus, dynamic changes of HRV during testing may reflect an adaptation to situational demands.

\section{Vagal Regulation, Attention, and Cognitive Control}

Vagal regulation is related to attention. When infants view objects, a greater deceleration of heart rate accompanies sustained attention (Richards 2003). It is also linked to enhanced processing of stimuli (Richards 2003) and lower distractibility (Lansink and Richards 1997; Richards and Gibson 1997). Furthermore, infants with higher baseline RSA are less distractible and show a greater task-related heart rate deceleration (Richards 1987).

A recent study showed that twelve-month-olds who were less reactive to negative stimuli and who showed more dynamic changes of arousal during a task had the highest ability to sustain attention (Wass et al. 2018). Another study demonstrated that changes in arousal preceded changes in attention (Wass et al. 2016). This suggests that adequate vagal regulation provides an optimal level of arousal for tasks engaging voluntary attention. The ability to regulate arousal according to situational demands, via its impact on attention, results in effective information processing and consequently in optimal task performance. 
Vagal regulation and executive functions share common neural substrates, with the prefrontal cortex being the highest-order regulator (Thayer et al. 2009). A neuroanatomical model elucidating two-way relations between the functioning of prefrontal cortical and subcortical structures and their peripheral effects (heart activity) was proposed by Thayer and Lane (2000). In adults, higher HRV is associated with better executive functioning and attention control (Hansen et al. 2003), irrespective of the level of stress induced by experimental conditions (Hansen et al. 2009). Consistent with these results, a study with children showed that at 3.5 years of age, children who had higher resting RSA and moderate RSA withdrawal during testing scored higher in executive functions tasks than children with other patterns of autonomic regulation and reactivity (Marcovitch et al. 2010).

\section{Atypical Vagal Regulation, Eye Contact, Attention, and Executive Functions in Autism Spectrum Disorders}

Vagal regulation varies across the typical population. Moreover, neurotypical individuals differ with regard to vagal regulation and executive functions from those with ASD. ASD is a group of neurodevelopmental disorders characterized by severe disturbances in social interaction and social communication (including eye contact), and restriction, repetitiveness, and rigidity of behavior or interests (World Health Organization 2018). Atypicalities in the development of different aspects of attention are prevalent in ASD (Fujioka et al. 2020; Hendry et al. 2020; Macari et al. 2020; Moriuchi et al. 2017; Vivanti et al. 2017), as are deficits in executive functions (Demetriou et al. 2018; Jones et al. 2018; Leung et al. 2016; Peng and Wallace 2017; Wallace et al. 2016).

Children with ASD show a lower baseline RSA and a lower RSA reactivity in comparison with typical controls (Porges et al. 2013). RSA grows slower with age in infants and toddlers with ASD than in typically developing controls (Sheinkopf et al. 2019). Among individuals with ASD, higher baseline RSA is associated with better social functioning and receptive language (Patriquin et al. 2013). Furthermore, higher RSA during an emotion recognition task is related to better performance (Bal et al. 2010). Therefore, in individuals with ASD, a pattern of RSA reactivity similar to the one observed in neurotypical individuals is associated with better functioning.

Children with ASD show a decreased RSA in response to pictures of unfamiliar faces, an indicator that the vagal brake has been turned on. This suggests that they react to certain novel social cues with a fight or flight response on a physiological level (Van Hecke et al. 2009). A withdrawal of the vagal brake while interacting with unfamiliar people could possibly account for the avoidance of eye contact and social withdrawal in ASD. This is consistent with the studies that showed a lack of positive effect of eye contact on cognitive performance in individuals with ASD (Falck-Ytter et al. 2015), and a lack of typical approach reactions to faces with direct gaze (Kylliäinen et al. 2012). This could also explain the lack of preferential looking at the eye region of unfamiliar adults in toddlers with autism (Jones et al. 2008). Thus, Porges and colleagues (Porges et al. 2013) propose that symptoms of ASD, such as deficits in social engagement, but also regulatory disorders and atypical auditory processing, may be explained by defective vagal regulation.

Although the polyvagal theory cannot account for all the symptoms of autism, it offers a promising perspective for studies of the influence of eye contact on executive functioning in neurotypical individuals and those with ASD by linking vagal regulation with responses to eye gaze and attention. This approach could help to elucidate the mechanisms underlying the eye contact effect and the face-to-face interference.

\section{Self-Regulation of Attention as a Tool to Optimize Affect and Cognitive Performance}

"Self-regulation refers to the many processes by which the human psyche exercises control over its functions, states, and inner processes" (Vohs and Baumeister 2004, p. 1). It is associated with the outcomes across various developmental areas throughout the life-span, such as health, academic achievement, and economic well-being (McClelland et al. 2018). Self-regulatory systems are organized hierarchically (Derryberry and Tucker 2006). Higher-order processes, such as voluntary control of attention, can regulate the lower-level, reactive processes (Derryberry 2002).

Attention plays an important role in the development of self-regulation (for a review see Berger et al. 2007). Improvements in attention control through training are associated with better self-regulation (Cavicchioli et al. 2020; Hanif et al. 2012). Attention-related strategies of selfregulation include withdrawing attention from a stimulus, shifting gaze, and refocusing attention on a different stimulus. For example, in a study of mother-infant face-to-face interactions, infants who averted gaze more frequently also smiled more (Stifter and Moyer 1991). Concurrently, a study with adults demonstrated that participants with a lower ability to disengage attention reported more negative affect (Compton 2000).

Looking away from stimuli during testing can have a similar function. This was demonstrated in a study with toddlers: those who had more off-task glances during an assessment with a developmental scale also had longer periods of sustained attention (Choudhury and Gorman 2000). Thus, withdrawing from eye contact, as well as shifting attention 
away from task stimuli, are attention-related strategies of selfregulation that individuals can use to optimize their affect and cognitive processing.

\section{Examining the Relations between Eye Contact and Vagal Regulation and Reactivity}

The existing literature gives rise to the following three hypotheses. First, the influence of eye contact on individuals' executive functioning depends on inter-individual differences in baseline vagal regulation and task-related vagal reactivity. Individuals with high baseline vagal regulation and moderate task-related vagal reactivity perform better when eye contact with an experimenter is present than when there is no eye contact because they are in a state optimal for social engagement. Individuals with low baseline vagal regulation and high or low task-related vagal reactivity perform better when there is no eye contact with an experimenter than when eye contact is present because the vagal brake is activated. Second, individuals use attention-related strategies of self-regulation to optimize task performance. The use of strategies varies with vagal regulation and reactivity. Participants with high baseline vagal regulation and moderate task-related vagal reactivity may, overall, have a tendency to use more eye contact and use more effective strategies. Participants with low baseline vagal regulation and high or low task-related vagal reactivity may use more gaze avoidance and regulate less effectively. Third, eye contact disturbs executive functioning of individuals with ASD and increases their use of various strategies of self-regulation. This effect is less prominent in individuals who show more optimal patterns of vagal regulation and reactivity.

In order to test these hypotheses, genuine eye contact during participant-experimenter interactions should be used as experimental manipulation. Although eye-tracking has been successfully used to study the eye contact effect (e.g., Dalmaso et al. 2017; Hadjikhani et al. 2018; Hoehl et al. 2014; Reid and Striano 2005), some responses to eye contact can only be observed in interactions with a live partner (e.g., Myllyneva \& Hietanen 2015; Hietanen and Hietanen 2017). A procedure involving eye contact with a live experimenter would increase the ecological validity of the study. This may be crucial when testing participants with ASD, as genuine social interactions are challenging for those individuals. Moreover, task performance of participants with ASD may be more strongly affected by the presence or absence of the eye contact with an experimenter than the performance of neurotypical participants.

The hypotheses could be tested by measuring participants' baseline HRV and changes in HRV during the administration of tasks engaging executive functions in two conditions: with and without eye contact with an experimenter. One possible task would be the backward digit span task, which assesses working memory (based on McCarthy 1972), and which was used by Falck-Ytter et al. (2015). Overall, a researcher would have to find a way to manipulate the eye contact variable while assessing executive functions. Concurrently, attentionrelated strategies of self-regulation should be observed. Intelligence level must be controlled, as well as temperament and severity of autistic symptoms in participants with ASD (or broad autistic phenotype in neurotypical participants). Finally, demographic data should be collected to account for possible effects of socioeconomic status.

\section{Conclusions}

In this paper, I reviewed studies that point to a possible modulation of the eye contact effect by vagal reactivity and regulation. The modulation hypothesis could be tested using a set of psychophysiological and behavioral measures in a controlled, yet ecologically valid setting. The ultimate aim of the research would be to develop a model of the impact of eye contact on executive functioning that takes into account an individual's baseline vagal regulation and task-related reactivity, and behavioral self-regulation of attention.

This model could influence the way the eye contact effect and face-to-face interference effect are understood by demonstrating that 1. individual differences in autonomic responses to eye contact determine its influence on cognition, 2. this effect is modified by attention-related self-regulation and 3 . the overall effect of eye contact on executive functioning depends on a complex interplay between physiological and behavioral responses to task demands. This model could help to better understand the complex mechanisms underlying differences in participant's cognitive performance in tasks engaging executive functions.

Availability of Data and Material Data sharing is not applicable to this article as no datasets were generated or analysed.

Code Availability Does not apply.

Funding The writing of this article was supported by the Faculty of Psychology, University of Warsaw, Warsaw, Poland (grant no. 5011000210).

\section{Declarations}

Ethical Statement No ethical approval was required.

Consent to Participate Consent to participate is not applicable to this article as this work did not involve data collection.

Conflict of Interest The author has no conflict of interest to declare. 
Open Access This article is licensed under a Creative Commons Attribution 4.0 International License, which permits use, sharing, adaptation, distribution and reproduction in any medium or format, as long as you give appropriate credit to the original author(s) and the source, provide a link to the Creative Commons licence, and indicate if changes were made. The images or other third party material in this article are included in the article's Creative Commons licence, unless indicated otherwise in a credit line to the material. If material is not included in the article's Creative Commons licence and your intended use is not permitted by statutory regulation or exceeds the permitted use, you will need to obtain permission directly from the copyright holder. To view a copy of this licence, visit http://creativecommons.org/licenses/by/4.0/.

\section{References}

Bal, E., Harden, E., Lamb, D., Van Hecke, A. V., Denver, J. W., \& Porges, S. W. (2010). Emotion recognition in children with autism spectrum disorders: Relations to eye gaze and autonomic state. Journal of Autism and Developmental Disorders, 40(3), 358-370. https://doi.org/10.1007/s10803-009-0884-3.

Berger, A., Kofman, O., Livneh, U., \& Henik, A. (2007). Multidisciplinary perspectives on attention and the development of self-regulation. Progress in Neurobiology, 82(5), 256-286. https:// doi.org/10.1016/j.pneurobio.2007.06.004.

Calkins, S. D. (1997). Cardiac vagal tone indices of temperamental reactivity and behavioral regulation in young children. Developmental Psychobiology, 31(2), 125-135.

Cavicchioli, M., Ramella, P., Vassena, G., Simone, G., Prudenziati, F., Sirtori, F., Movalli, M., \& Maffei, C. (2020). Mindful self-regulation of attention is a key protective factor for emotional dysregulation and addictive behaviors among individuals with alcohol use disorder. Addictive Behaviors Addictive Behaviors, 105, 106317. https:// doi.org/10.1016/j.addbeh.2020.106317.

Choudhury, N., \& Gorman, K. S. (2000). The relationship between sustained attention and cognitive performance in 17-24-month old toddlers. Infant and Child Development, 9(3), 127-146.

Compton, R. J. (2000). Ability to disengage attention predicts negative affect. Cognition \& Emotion, 14(3), 401-415. https://doi.org/10. 1080/026999300378897.

Conty, L., Gimmig, D., Belletier, C., George, N., \& Huguet, P. (2010). The cost of being watched: Stroop interference increases under concomitant eye contact. Cognition, 115, 133-139. https://oi.org/10. 1016/j.cognition.2009.12.005.

Dalmaso, M., Castelli, L., Scatturin, P., \& Galfano, G. (2017). Trajectories of social vision: Eye contact increases saccadic curvature. Visual Cognition, 25(1-3), 358-365. https://doi.org/10.1080/ 13506285.2017.1290727.

Demetriou, E. A., Lampit, A., Quintana, D. S., Naismith, S. L., Song, Y. J. C., Pye, J. E., \& Guastella, A. J. (2018). Autism spectrum disorders: A meta-analysis of executive function. Molecular Psychiatry, 23(5), 1198-1204. https://doi.org/10.1038/mp.2017.75.

Derryberry, D. (2002). Attention and voluntary self-control. Self and Identity, 1(2), 105-111. https://doi.org/10.1080/ 152988602317319276

Derryberry, D., \& Tucker, D. M. (2006). Motivation, self-regulation and self organization. In D. Cohen \& D. Cicchetti (Eds.), Developmental psychopathology (Vol. 2, pp. 502-529). New York: Wiley.

Diamond, A. (2013). Executive functions. Annual Review of Psychology, 64, 135-168. https://doi.org/10.1146/annurev-psych-113011143750.

Falck-Ytter, T., Carlström, C., \& Johansson, M. (2015). Eye contact modulates cognitive processing differently in children with autism.
Child Development, 86(1), 37-47. https://doi.org/10.1111/cdev. 12273.

Farroni, T., Johnson, M. H., \& Csibra, G. (2004). Mechanisms of eye gaze perception during infancy. Journal of Cognitive Neuroscience, 16(8), 1320-1326. https://doi.org/10.1162/0898929042304787.

Fujioka, T., Tsuchiya, K. J., Saito, M., Hirano, Y., Matsuo, M., Kikuchi, M., \& Yoshimura, Y. (2020). Developmental changes in attention to social information from childhood to adolescence in autism spectrum disorders: A comparative study. Molecular Autism, 11, 1-17. https://doi.org/10.1186/s13229-020-00321-w.

Gentzler, A. L., Santucci, A. K., Kovacs, M., \& Fox, N. A. (2009). Respiratory sinus arrhythmia reactivity predicts emotion regulation and depressive symptoms in at-risk and control children. Biological Psychology, 82(2), 156-163. https://doi.org/10.1016/j.biopsycho. 2009.07.002.

Hadjikhani, N., Johnels, J. Å., Lassalle, A., Zürcher, N. R., Hippolyte, L., Gillberg, C., \& Ben-Ari, Y. (2018). Bumetanide for autism: More eye contact, less amygdala activation. Scientific Reports, 8(1), 1-8. https://doi.org/10.1038/s41598-018-21958-x.

Hanif, A., Ferrey, A. E., Frischen, A., Pozzobon, K., Eastwood, J. D., Smilek, D., \& Fenske, M. J. (2012). Manipulations of attention enhance self-regulation. Acta Psychologica, 139(1), 104-110. https://doi.org/10.1016/j.actpsy.2011.09.010.

Hansen, A. L., Johnsen, B. H., Sollers, J. J., Stenvik, K., \& Thayer, J. F. (2004). Heart rate variability and its relation to prefrontal cognitive function: The effects of training and detraining. European Journal of Applied Physiology, 93(3), 263-272. https://doi.org/10.1007/ s00421-004-1208-0.

Hansen, A. L., Johnsen, B. H., \& Thayer, J. F. (2003). Vagal influence on working memory and attention. International Journal of Psychophysiology, 48(3), 263-274. https://doi.org/10.1016/S01678760(03)00073-4.

Hansen, A. L., Johnsen, B. H., \& Thayer, J. F. (2009). Relationship between heart rate variability and cognitive function during threat of shock. Anxiety, Stress, \& Coping, 22(1), 77-89. https://doi.org/ 10.1080/10615800802272251.

Helminen, T. M., Kaasinen, S. M., \& Hietanen, J. K. (2011). Eye contact and arousal: The effects of stimulus duration. Biological Psychology, 88(1), 124-130. https://doi.org/10.1016/j.biopsycho. 2011.07.002.

Hendry, A., Jones, E. J., Bedford, R., Andersson Konke, L., Begum Ali, J., Bölte, S., \& Roeyers, H. (2020). Atypical development of attentional control associates with later adaptive functioning, autism and ADHD traits. Journal of Autism and Developmental Disorders., 50, 4085-4105. https://doi.org/10.1007/s10803-020-04465-9.

Hessels, R. S. (2020). How does gaze to faces support face-to-face interaction? A review and perspective. Psychonomic Bulletin \& Review, 27, 1-26. https://doi.org/10.3758/s13423-020-01715-w.

Hietanen, J. K., Leppänen, J. M., Peltola, M. J., Linna-aho, K., \& Ruuhiala, H. J. (2008). Seeing direct and averted gaze activates the approach-avoidance motivational brain systems. Neuropsychologia, 46(9), 2423-2430. https://doi.org/10.1016/j. neuropsychologia.2008.02.029.

Hietanen, J. K., Myllyneva, A., Helminen, T. M., \& Lyyra, P. (2016). The effects of genuine eye contact on visuospatial and selective attention. Journal of Experimental Psychology: General, 145(9), 11021106. https://doi.org/10.1037/xge0000199.

Hietanen, J. O., \& Hietanen, J. K. (2017). Genuine eye contact elicits selfreferential processing. Consciousness and Cognition, 51, 100-115. https://doi.org/10.1016/j.concog.2017.01.019.

Hietanen, J. K., Helminen, T. M., Kiilavuori, H., Kylliäinen, A., Lehtonen, H., \& Peltola, M. J. (2018). Your attention makes me smile: Direct gaze elicits affiliative facial expressions. Biological Psychology, 132, 1-8. https://doi.org/10.1016/j.biopsycho.2017. 11.001 . 
Hoehl, S., Wahl, S., \& Pauen, S. (2014). Disentangling the effects of an adult model's eye gaze and head orientation on young infants' processing of a previously attended object. Infancy, 19(1), 53-64. https://doi.org/10.1111/infa.12035.

Jones, C. R., Simonoff, E., Baird, G., Pickles, A., Marsden, A. J., Tregay, J., \& Charman, T. (2018). The association between theory of mind, executive function, and the symptoms of autism spectrum disorder. Autism Research, 11(1), 95-109. https://doi.org/10.1002/aur.1873.

Jones, W., Carr, K., \& Klin, A. (2008). Absence of preferential looking to the eyes of approaching adults predicts level of social disability in 2year-old toddlers with autism spectrum disorder. Archives of General Psychiatry, 65(8), 946-954. https://doi.org/10.1001/ archpsyc.65.8.946.

Kajimura, S., \& Nomura, M. (2016). When we cannot speak: Eye contact disrupts resources available to cognitive control processes during verb generation. Cognition, 157, 352-357. https://doi.org/10.1016/ j.cognition.2016.10.002.

Kylliäinen, A., Wallace, S., Coutanche, M. N., Leppänen, J. M., Cusack, J., Bailey, A. J., \& Hietanen, J. K. (2012). Affective-motivational brain responses to direct gaze in children with autism spectrum disorder. Journal of Child Psychology and Psychiatry, 53(7), 790797. https://doi.org/10.1111/j.1469-7610.2011.02522.x.

Lansink, J. M., \& Richards, J. E. (1997). Heart rate and behavioral measures of attention in six-, nine-, and twelve-month-old infants during object exploration. Child Development, 68(4), 610-620. https://doi. org/10.1111/j.1467-8624.1997.tb04224.x.

Leung, R. C., Vogan, V. M., Powell, T. L., Anagnostou, E., \& Taylor, M. J. (2016). The role of executive functions in social impairment in autism Spectrum disorder. Child Neuropsychology, 22(3), 336-344. https://doi.org/10.1080/09297049.2015.1005066.

Macari, S., Milgramm, A., Reed, J., Shic, F., Powell, K. K., Macris, D., \& Chawarska, K. (2020). Context-specific dyadic attention vulnerabilities during the first year in infants later developing autism Spectrum disorder. Journal of the American Academy of Child \& Adolescent Psychiatry, 60, 166-175. https://doi.org/10.1016/j.jaac.2019.12.012.

Marcovitch, S., Leigh, J., Calkins, S. D., Leerks, E. M., O'brien, M., \& Blankson, A. N. (2010). Moderate vagal withdrawal in 3.5-year-old children is associated with optimal performance on executive function tasks. Developmental Psychobiology, 52(6), 603-608. https:// doi.org/10.1002/dev.20462.

McCarthy, D. A. (1972). McCarthy scales of children's abilities. Psychological Corporation.

McClelland, M., Geldhof, J., Morrison, F., Gestsdóttir, S., Cameron, C., Bowers, E., \& Grammer, J. (2018). Self-regulation. In N. Halfon, C.B. Forrest, R. M. Lerner, \& E. M. Faustman, Handbook of Life Course Health Development (pp. 275-298). Springer, Cham, SelfRegulation.

Moriuchi, J. M., Klin, A., \& Jones, W. (2017). Mechanisms of diminished attention to eyes in autism. American Journal of Psychiatry, 174(1), 26-35. https://doi.org/10.1176/appi.ajp.2016.15091222.

Myllyneva, A., \& Hietanen, J. K. (2015). There is more to eye contact than meets the eye. Cognition, 134, 100-109. https://doi.org/10. 1016/j.cognition.2014.09.011.

Niedźwiecka, A. (2020). Look me in the eyes: Mechanisms underlying the eye contact effect. Child Development Perspectives, 14(2), 7882. https://doi.org/10.1111/cdep.12361.

Patriquin, M. A., Scarpa, A., Friedman, B. H., \& Porges, S. W. (2013). Respiratory sinus arrhythmia: A marker for positive social functioning and receptive language skills in children with autism spectrum disorders. Developmental Psychobiology, 55(2), 101-112. https:// doi.org/10.1002/dev.21002.

Peng, C. S., \& Wallace, G. L. (2017). Profiles of executive control in autism Spectrum disorder, attention deficit hyperactivity disorder, and Tourette's syndrome. In L.C. Centifanti \& D.M. Williams (Eds.), The Wiley Handbook of Developmental Psychopathology (pp. 87-137). John Wiley \& Sons.
Phelps, F. G., Doherty-Sneddon, G., \& Warnock, H. (2006). Helping children think: Gaze aversion and teaching. British Journal of Developmental Psychology, 24, 577-588. https://doi.org/10.1348/ $026151005 X 49872$

Porges, S. W. (2007). The polyvagal perspective. Biological Psychology, 74(2), 116-143. https://doi.org/10.1016/j.biopsycho.2006.06.009.

Porges, S. W., Macellaio, M., Stanfill, S. D., McCue, K., Lewis, G. F., Harden, E. R., \& Heilman, K. J. (2013). Respiratory sinus arrhythmia and auditory processing in autism: Modifiable deficits of an integrated social engagement system? International Journal of Psychophysiology, 88(3), 261-270. https://doi.org/10.1016/j. ijpsycho.2012.11.009.

Prinsen, J., Deschepper, A., Maes, E., \& Alaerts, K. (2019). Attachment styles have a modulatory impact on psychophysiological arousal evoked by reciprocated and unreciprocated gaze. Biological Psychology, 148(107773), 107773. https://doi.org/10.1016/j. biopsycho.2019.107773.

Reid, V. M., \& Striano, T. (2005). Adult gaze influences infant attention and object processing: Implications for cognitive neuroscience. European Journal of Neuroscience, 21(6), 1763-1766. https://doi. org/10.1111/j.1460-9568.2005.03986.x.

Richards, J. E. (1987). Infant visual sustained attention and respiratory sinus arrhythmia. Child Development, 58(2), 488-496. https://doi. org/10.1111/j.1469-8986.1989.tb01944.x.

Richards, J. E. (2003). Attention affects the recognition of briefly presented visual stimuli in infants: An ERP study. Developmental Science, 6(3), 312-328. https://doi.org/10.1111/1467-7687.00287.

Richards, J. E., \& Gibson, T. L. (1997). Extended visual fixation in young infants: Look distributions, heart rate changes, and attention. Child Development, 68(6), 1041-1056. https://doi.org/10.1111/j.14678624.1997.tb01983.x.

Riby, D. M., Doherty-Sneddon, G., \& Whittle, L. (2012). Face-to-face interference in typical and atypical development. Developmental Science, 15, 281-291. https://doi.org/10.1111/j.1467-7687.2011. 01125.x.

Sheinkopf, S. J., Levine, T. P., McCormick, C. E., Puggioni, G., Conradt, E., Lagasse, L. L., \& Lester, B. M. (2019). Developmental trajectories of autonomic functioning in autism from birth to early childhood. Biological Psychology, 142, 13-18. https://doi.org/10.1016/j. biopsycho.2019.01.003.

Segerstrom, S. C., \& Nes, L. S. (2007). Heart rate variability reflects selfregulatory strength, effort, and fatigue. Psychological Science, 18(3), 275-281. https://doi.org/10.1111/j.1467-9280.2007.01888.x.

Senju, A., \& Johnson, M. H. (2009). The eye contact effect: Mechanisms and development. Trends in Cognitive Sciences, 13(3), 127-134. https://doi.org/10.1016/j.tics.2008.11.009.

Suess, P. E., Porges, S. W., \& Plude, D. J. (1994). Cardiac vagal tone and sustained attention in school-age children. Psychophysiology, 31(1), 17-22. https://doi.org/10.1111/j.1469-8986.1994.tb01020.x.

Stifter, C. A., \& Moyer, D. (1991). The regulation of positive affect: Gaze aversion activity during mother-infant interaction. Infant Behavior and Development, 14(1), 111-123. https://doi.org/10.1016/01636383(91)90058-Z.

Thayer, J. F., Hansen, A. L., Saus-Rose, E., \& Johnsen, B. H. (2009). Heart rate variability, prefrontal neural function, and cognitive performance: The neurovisceral integration perspective on self-regulation, adaptation, and health. Annals of Behavioral Medicine, 37(2), 141-153. https://doi.org/10.1007/s12160-009-9101-z.

Thayer, J. F., \& Lane, R. D. (2000). A model of neurovisceral integration in emotion regulation and dysregulation. Journal of Affective Disorders, 61(3), 201-216. https://doi.org/10.1016/S01650327(00)00338-4.

Van Hecke, A. V., Lebow, J., Bal, E., Lamb, D., Harden, E., Kramer, A., \& Porges, S. W. (2009). Electroencephalogram and heart rate regulation to familiar and unfamiliar people in children with autism 
spectrum disorders. Child Development, 80(4), 1118-1133. https:// doi.org/10.1111/j.1467-8624.2009.01320.x.

Vivanti, G., Fanning, P. A., Hocking, D. R., Sievers, S., \& Dissanayake, C. (2017). Social attention, joint attention and sustained attention in autism Spectrum disorder and Williams syndrome: Convergences and divergences. Journal of Autism and Developmental Disorders, 47(6), 1866-1877. https://doi.org/10.1007/s10803-017-3106-4.

Vohs, K. D., \& Baumeister, R.F. (2004). An introduction. In R. F Baumeister, \& K. D. Vohs (Eds.), Handbook of self-regulation: Research, theory and application (pp. 1-9). New York: Guilford Press.

Wallace, G. L., Kenworthy, L., Pugliese, C. E., Popal, H. S., White, E. I., Brodsky, E., \& Martin, A. (2016). Real-world executive functions in adults with autism spectrum disorder: Profiles of impairment and associations with adaptive functioning and co-morbid anxiety and depression. Journal of Autism and Developmental Disorders, 46(3), 1071-1083. https://doi.org/10.1007/s10803-015-2655-7.

World Health Organization. (2018). International classification of diseases for mortality and morbidity statistics (11th Revision). https:// icd.who.int/browse11/1-m/en
Wass, S. V., Clackson, K., \& de Barbaro, K. (2016). Temporal dynamics of arousal and attention in 12-month-old infants. Developmental Psychobiology, 58(5), 623-639. https://doi.org/10.1002/dev.21406.

Wass, S. V., de Barbaro, K., Clackson, K., \& Leong, V. (2018). New meanings of thin-skinned: The contrasting attentional profiles of typical 12-month-olds who show high, and low, stress reactivity. Developmental Psychology, 54(5), 816-828. https://doi.org/10. 1037/dev0000428.

Wieser, M. J., Pauli, P., Alpers, G. W., \& Mühlberger, A. (2009). Is eye to eye contact really threatening and avoided in social anxiety? - an eye-tracking and psychophysiology study. Journal of Anxiety Disorders, 23(1), 93-103. https://doi.org/10.1016/j.janxdis.2008. 04.004 .

Wu, R., Tummeltshammer, K. S., Gliga, T., \& Kirkham, N. Z. (2014). Ostensive signals support learning from novel attention cues during infancy. Frontiers in Psychology, 5(251). https://doi.org/10.3389/ fpsyg.2014.00251.

Publisher's Note Springer Nature remains neutral with regard to jurisdictional claims in published maps and institutional affiliations. 